\title{
Ray of hope for the East
}

\section{Munich}

RESEARCHERS in eastern Germany received an important vote of confidence two weeks ago from the Fraunhofer Gesellschaft, a Munich-based organization that supports and directs scientific research at several dozen institutes in western Germany. The Gesellschaft announced that it will create 19 research institutes and outstations in the former East Germany by merging existing groups from a variety of institutions, thus making it more likely that these groups will survive the turmoil brought on by merging science in the east and west.

By pledging DM500 million (about $\$ 281$ million) to the 19 institutes, the Gesellschaft, a non-profit research organization with ties to government and industry, is making the biggest single commitment to research in eastern Germany since German unification.

Although it will affect only certain fields of applied research, the Gesellschaft's support is encouraging for researchers who had begun to wonder whether the West would see any value at all in their work.

The decision is also seen as a step towards rebuilding the collapsing industrial base of eastern Germany. The small- and mediumsized companies, known as the Mittelstand, which form the backbone of Germany's industrial economy, often depend on having publicly funded research and development activity nearby.

Now, with the Gesellschaft's action, "there will be a higher density of Fraunhofer institutes in eastern Germany than there is in western Germany," says Wilhelm Krull of the science advisory council Wissenschaftsrat, which had a hand in deciding which groups to take over. By setting up a dense network of application-orientated research centres, Krull says, Fraunhofer Gesellschaft is providing a foundation upon which new or revamped industry can build.

Between 1992 and the end of 1994, the Gesellschaft will distribute the DM500 million among the 19 institutions - ten new institutes and nine outstations of existing western institutes. In addition, the Gesellschaft seeks an additional DM70 million to set up even more institutes. The move is expected to save the jobs of at least 950 researchers and supporting staff.

By moving quickly and decisively into eastern Germany, Fraunhofer Gesellschaft has put pressure on the German government to raise its level of commitment to the eastern part of the country. The governments in Bonn and the Länder (states) will have to pour in at least another DM300 million just to renovate the dilapidated buildings in which the institutes are housed and make them fit for modern research. Even more money will be required for modern research equipment, especially computers compatible with those used in industry. "We are counting on Bonn and the Länder to help." says Gesellschaft spokesman Alexander Rothhämel.

All 19 institutions will be composed of researchers who worked in East German institutes, universities or industry. Like the general working population, eastern German research workers face an uncertain future now that their organizations, especially the East German Academy of Sciences, are being shut down or reorganized.

Among those fortunate enough to be selected are a number of groups that used to work at the academy, which in the years before unification had been shifting its emphasis increasingly towards applied research. Because of export restrictions on high technology, the academy and East German industry were forced to develop on their own technologies that were widely available in the West. In the process, eastern Germans developed a technological resourcefulness that is impressive to their Western colleagues. The Gesellschaft decision is a concrete indication that they have not been working for naught.

If the new institutes are to survive past their initial three-year period of support by the Gesellschaft, they will have to generate revenue by doing contract research for industry. The Gesellschaft has said it expects the institutes to cover 25 per cent of their costs through contract research. The 38 Fraunhofer Institutes in the west generally cover about 80 per cent of their costs through outside contracts. But the Gesellschaft recognizes that it will take time for the eastern institutes to discover the most profitable fields of research.

The list of groups and institutes to be taken over includes no surprises; among them are the Academy institutes thought to have the best chance of surviving in a united Germany. The significance of the decision by Fraunhofer is that related groups will be allowed to keep working together rather than having to take their chances on the open market. One example is the central institute for cybernetics and information processing in East Berlin, where, in the transition phase before unification, clever programmers had already found western contracts to augment their income. Other fields on the list include solid state physics, ceramics, polymer chemistry and applied optics.

The Gesellschaft left itself two ways out in case the research services that its eastern institutes provide prove to be superfluous. After three years, the Gesellschaft may either close the institutes or move some of the researchers to related western institutes.

Because a move to the west goes against Bonn's philosophy about unifying German research - namely, to keep as much of eastern research as possible in the east - a Gesellschaft spokesman says he expects such a westward shift to occur in only a small number of cases.
Auditors fret,
NASA persists

\section{Washington}

Controversy over the price of the planned international space station - the one constant in the embattled project's tumultuous decade of design - has struck again. A new US government accounting audit shows that the space station may eventually cost as much as $\$ 40,000$ million more than expected. Coupled with an emerging consensus from the scientific community that, as now designed, the space station will be of minimal scientific use, the news may set the stage for the toughest battle yet in Congress over the future of the project.

The audit, by the congressional General Accounting Office (GAO), found that NASA (the National Aeronautics and Space Administration) had not included the costs of such items as a crew-escape module and a artificial-gravity centrifuge in its estimates to Congress. NASA also neglected to include the costs of maintaining and operating the station once it is completed, GAO said.

"Once these costs are added together," GAO comptroller general Charles Bowsher testified at a congressional hearing last week, "what we actually have is at least a $\$ 118$ billion program - about $\$ 40$ billion to achieve permanent occupancy and about $\$ 78$ billion to keep the station operational between 2000 and 2027." In defence of the project, senior NASA officials dismissed the audit findings as a matter of differing accounting methodologies and called for an end to such reviews. "It's time to come to a decision," testified NASA administrator Richard Truly. "Let's give it to the engineers and let them go build it."

Since 1984, NASA has redesigned the space station eight times to adapt to new technical, financial and congressional demands. In the process, the station has shrunk from an eight-person, six-module, $125-\mathrm{kW}$ design whose development was expected to cost $\$ 8,000$ million to a fourperson, three-module, $56-\mathrm{kW}$ design expected to cost $\$ 16,900$ million to develop and $\$ 13,000$ million to deploy. In development alone, NASA's expects to pay twice its 1984 estimate for half as much station. And if GAO is right, the real cost may be even higher - $\$ 10,000$ million more in the development phase and $\$ 34,000$ million over NASA's estimates during the operating phase.

The history of such space station controversies has been consistent. Each new study has revealed that the project will probably cost more and deliver less science than previously promised. Each time, the grim figures have prompted new calls for the project's cancellation. Yet, so far, the US champions of the project have been able successfully to argue that it should still be built.

Christopher Anderson 